\title{
Kinetics and Thermodynamics of Ultrasound-Assisted Depolymerization of k-Carrageenan
}

\author{
R. Ratnawati*, Aji Prasetyaningrum, Dyah Hesti Wardhani \\ Department of Chemical Engineering, Diponegoro University, Jl. Prof. Soedarto, Kampus Undip \\ Tembalang, Semarang 50275, Indonesia
}

Received: 10 $0^{\text {th }}$ November 2015; Revised: 18 th January 2016; Accepted: $19^{\text {th }}$ January 2016

\begin{abstract}
The ultrasound-assisted depolymerization of $\mathrm{k}$-carrageenan has been studied at various temperatures and times. The $\mathrm{k}$-carrageenan with initial molecular weight of $545 \mathrm{kDa}$ was dispersed in water to form a $5 \mathrm{~g} / \mathrm{L}$ solution, which was then depolymerized in an ultrasound device at various temperatures and times. The viscosity of the solution was measured using Brookfield viscometer, which was then used to find the number-average molecular weight by Mark-Houwink equation. To obtain the kinetics of $\mathrm{k}$ carrageenan depolymerization, the number-average molecular weight data was treated using midpoint-chain scission kinetics model. The pre-exponential factor and activation energies for the reaction are $2.683 \times 10^{-7} \mathrm{~mol} \mathrm{~g}^{-1} \mathrm{~min}^{-1}$ and $6.43 \mathrm{~kJ} \mathrm{~mol}^{-1}$, respectively. The limiting molecular weight varies from $160 \mathrm{kDa}$ to $240 \mathrm{kDa}$, and it is linearly correlated to temperature. The results are compared to the result of thermal depolymerization by calculating the half life. It is revealed that ultrasound assisted depolymerization of $\mathrm{k}$-carrageenan is faster than thermal depolymerization at temperatures below $72.2^{\circ} \mathrm{C}$. Compared to thermal depolymerization, the ultrasound-assisted process has lower values of $E_{a}$, $\Delta G^{\ddagger}, \Delta H^{\ddagger}$, and $\Delta S^{\ddagger}$, which can be attributed to the ultrasonically induced breakage of non-covalent bonds in k-carrageenan molecules. Copyright (C) 2016 BCREC GROUP. All rights reserved
\end{abstract}

Keywords: Depolymerization; Half life; Limiting molecular weight; Midpoint-chain scission; кcarrageenan

How to Cite: Ratnawati, R., Prasetyaningrum, A., Wardhani, D.H. (2016). Kinetics and Thermodynamics of Ultrasound-Assisted Depolymerization of к-Carrageenan. Bulletin of Chemical Reaction Engineering \& Catalysis, 11(1): 48-58. (doi:10.9767/bcrec.11.1.415.48-58)

Permalink/DOI: http://dx.doi.org/10.9767/bcrec.11.1.415.48-58

\section{Introduction}

Carrageenan is a sulfated galactan extracted from red algae (Rhodophyceae), which is abundantly available in Indonesian waters. The basic structure of carrageenan is potassium, sodium, calcium, magnesium, or ammonium sulfate ester of D-galactose polymer

* Corresponding Author.

E-mail: : ratnawati_hartono@undip.ac.id (R.

Ratnawati). Ph.: +62-24-7460058, Fax: +62-24-

76480675 linked in $\alpha-1,3$ and $\beta-1,4$ positions. The structure is depicted in Figure 1.

Carrageenan is utilized in food industries as thickening, gelling, and stabilizing agents [1]. Attempts have been conducted to broaden the utilization of carrageenan, one of which is through depolymerization. The oligomers or the low molecular weight fraction (LMWF) of carrageenan as the result of depolymerization is subjected to biomedical applications. It was reported that the LMWF carrageenan had activity to inhibit tumor growth [2-4]. The LMWF carrageenan was also reported to have antiher- 
petic [5], antivirus [6, 7], anticoagulant [6-9], and antioxidant [9- 10] activities.

Many methods have been used to depolymerize carrageenan, such as thermal depolymerization [11], acid hydrolysis [12-16], enzymatic hydrolysis $[3,15,17,18]$, irradiation $[10$, 19], and sonication [20, 21]. Thermal treatment on $\mathrm{k}$-carrageenan is faster at higher temperatures [11]. However, even at $95{ }^{\circ} \mathrm{C}$, the reaction is much slower compared to acid [12] and enzymatic [18], and it is comparable to sonolytic depolymerization [20]. Chemical treatment often causes excessive depolymerization, consumes extensive time and energy, and involves chemicals which may generate waste. Enzymatic depolymerization, either using specific or non-specific enzymes, is a relatively expensive and complex process [22]. Those facts drive the development of ultrasonic-assisted depolymerization as it is cheap, simple, energysaving, and suitable for food [23]. The ultrasonication is usually applied to solution or suspension of polysaccharides [22].

When ultrasound is irradiated to a liquid, it will generate pressure wave on the liquid which will further results in the formation and collapse of bubbles. This phenomenon is called cavitations. The rapid collapse of the bubble causes high pressure gradients and high local velocities of liquid layer in its vicinity. This may cause shear force that is capable of breaking the covalent bond of polymers, provided the chains are longer than a certain limiting value $[22,24]$. The collapse of the bubble can also produce intense local heating and high pressures with lifetime in the order of $10^{-10} \mathrm{~s}$ [25]. The temperature and the pressure can reach as high as $5000 \mathrm{~K}$ and $1000 \mathrm{~atm}$, respectively, in the gas phase of the collapsing bubble and above $1000 \mathrm{~K}$ in the thin layer of liquid adjacent to the cavity [26]. The hot spot may cause dissociation of water molecules to give hydrogen and hydroxyl radicals [27].

There have been many studies on kinetics of ultrasound-assisted depolymerization. Madras et al. [28] studied the kinetics of ultrasoundassisted depolymerization of poly(vinyl acetate)

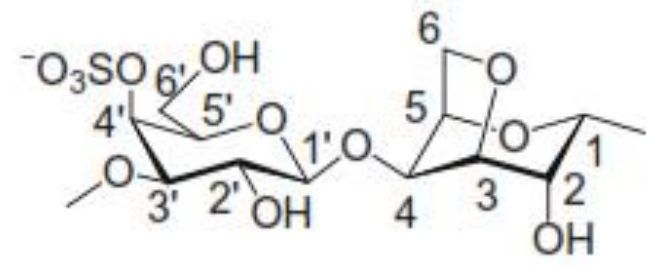

Figure 1. Basic structure of $\mathrm{k}$-carrageenan [1] in chlorobenzene, while Chakraborty et al. [29] investigated the kinetics of ultrasonic degradation of polybutadiene and isotactic polypropylene in solution at different temperatures and in different solvents. Other studies on chitosan [30], apple pectin [31], sea cucumber fucoidan [32], linear poly(phthalaldehyde) [33], carboxylic curdlan [34], and carrageenan [20, 21] have also been reported. Lii et al. [20] studied the effect of $\mathrm{k}$-carrageenan concentration on the kinetics of the reaction. They ran the experiment only at $50^{\circ} \mathrm{C}$. They utilized the pseudo-firstorder model like acid hydrolysis to describe the kinetics of ultrasonic depolymerization reaction. They found that the rate constant depended notably on time and, hence, molecular size. Such time dependence is quite unlike the linearity of acid hydrolysis $[12,13]$, so they concluded that the pseudo-first-order model was not suitable in describing the degradation kinetics over ultrasonication process. Most recently, Taghizadeh and Abdollahi [21] studied the effect of ultrasonic power and addition of $\mathrm{TiO}_{2}$ on the kinetics of ultrasonic degradation of $\mathrm{k}$-carrageenan at $25^{\circ} \mathrm{C}$. Instead of using the pseudo-first-order model, they considered the order of reaction along with the rate constant as the adjustable parameters in fitting the kinetic model to the experimental data. They found that the order of the reaction was negative with respect to the molar concentration of the polymer.

The reports on the study of the effect of temperature on the kinetics and thermodynamics of ultrasonic depolymerization of $\mathrm{K}$ carrageenan are not available in the literature to the moment. Therefore, the aim of this work is to study the effect of temperature on the kinetics and thermodynamics of ultrasoundassisted depolymerization of $\mathrm{k}$-carrageenan.

\section{Materials and Methods}

\subsection{Materials}

The raw material used in this work was $\mathrm{K}$ carrageenan derived from seaweed Kappaphycus alvarezii, which was produced by CV. Karagen Indonesia, Semarang, Indonesia. The carrageenan was dissolved in distilled water to form a $5 \mathrm{~g} / \mathrm{L}$ solution. The solution was placed in a $40 \mathrm{~mm}$ diameter and $120 \mathrm{~mm}$ height glass vessel. The mixture was heated to $60^{\circ} \mathrm{C}$ and stirred for 15 minutes.

\subsection{Ultrasound treatment}

Two hundred milliliters of sample was brought to specified temperatures $(30,40,50$, 
and $60{ }^{\circ} \mathrm{C}$ ) and put into ultrasound device, Krisbow type KLS 303365, with frequency of 42 $\mathrm{kHz}$. The device was equipped with thermostatic water bath. To minimize error due to uneven power transfer and temperature fluctuation during the ultrasonic process, the sample was placed right above the ultrasound source. The process was run in various times $(0,16,32$, $48,64,80,96,112,128,144$ minutes).

\subsection{Measurement of viscosity}

The viscosity of the $\mathrm{K}$-carrageenan in aqueous $0.1 \mathrm{M} \mathrm{NaCl}$ solution was measured using Brookfield viscometer of RDVE model. The solution was put in the sample container placed in water bath to equilibrate the temperature to $65 \pm 0.1^{\circ} \mathrm{C}$. Spindle number 2 was then immersed into the sample to the groove of the shaft. The speed of the spindle was set at 60 $\mathrm{rpm}$, then the viscometer was started and the reading was made at constant reading. The measurement was done in triplicate.

\subsection{Mathematical treatment for intrinsic viscosity}

The intrinsic viscosity $[\eta]$ was calculated from the specific viscosity $\left(\eta_{s p}\right)$ obtained from the Brookfield viscometer readings. The intrinsic viscosity is the average intercept of Huggins and Kraemer equation [35] in Equation (1).

$$
\frac{\eta_{s p}}{c}=[\eta]+k_{H}[\eta]^{2} c
$$

where $\eta_{s p},[\eta], k_{H}$, and $c$ are specific and intrinsic viscosity, Huggins constant, and the concentration of the solution, respectively. The specific viscosity $\left(\eta_{s p}\right)$ and the Huggin constant $\left(k_{H}\right)$ are dimensionless, while the intrinsic viscosity $([\eta])$ and the concentration $(c)$ have the units of $\mathrm{mL} / \mathrm{g}$ and $\mathrm{g} / \mathrm{mL}$, respectively. The value of $\boldsymbol{k}_{\boldsymbol{H}}$ for $\mathrm{K}$-carrageenan solution is 0.35 [35].

The molecular weight of $\mathrm{k}$-carrageenan $(M)$ is related to its viscosity by Mark Houwink equation [35] in Equation (2).

$$
[\eta]=k_{M H} M^{a}
$$

where $k_{M H}$ and $a$ are constants for a given system. In this work, the values of $k_{M H}$ and $a$ for $\mathrm{K}$ carrageenan are 0.00598 and 0.90 , respectively. $M$ and $[\eta]$ are expressed in $\mathrm{g} / \mathrm{gmol}$ and $\mathrm{mL} / \mathrm{g}$, respectively [20].

\subsection{Mathematical treatment for kinetics model}

In a depolymerization, all bonds of a polymer chain are equally susceptible to break with the rate proportional to the remaining unbroken bonds following a pseudo-first-order rate relation [36] in Equation (3).

$$
-\frac{d\left(N_{0} p\right)}{d t}=k_{p f} N_{0} p
$$

where $N_{o}$ denotes initial number of monomer in the reaction mixture, $p$ is fraction of monomers bonded in polymers, and $k_{p f}$ is the pseudo-firstorder reaction rate constant. The equation can be integrated from $t=0$ to $t=t$ to yield Equation (4).

$$
p=p_{0} e^{-k_{p f} t}
$$

For short reaction time with only small fraction of bonds is broken, $e^{-k p f t}$ can be approximated by $1-k_{p f} t$, and Equation (4) becomes Equation (5).

$$
p=p_{0}\left(1-k_{p f} t\right)
$$

Fraction of monomers bonded in polymers, $p$, can be related to number-average molecular weight of polymer [36] as Equation (6).

$$
p=1-\frac{m}{M_{t}}
$$

where $M_{t}$ is the number-average molecular weight of polymer at time $t$ and $m$ is the average molecular weight of monosaccharide unit. Based on the assumption that $a(1 \rightarrow 3)$ and $\beta$ $(1 \rightarrow 4)$ glycosidic linkages show similar susceptibility to breakage by ultrasound, the value of $m$ is 192 [11, 20]. In terms of molecular weight of polymer, Equation (6) is simplified to Equation (7).

$$
\frac{1}{M_{t}}=\frac{1}{M_{0}}+\frac{k_{p f}}{m} t
$$

where $M_{0}$ is the number-average molecular weight of polymer at time 0 . A plot of $1 / M_{t}$ versus $t$ produces a linear relationship from which the rate constant can be deduced from the gradient. 
Other model was developed based on midpoint-chain scission mechanism in mechanical degradation, for example, by ultrasonic radiation [37]. The degradation yields two molecules with nearly the same size. The breaking of the covalent bond of polymers continues up to a certain limiting molecular weight $[22,29]$, i.e. $M_{\infty}$. Using a continuous distribution model, Chakraborty et al. [29] derived the kinetics model in Equation (8).

$$
\ln \left(\frac{1}{M_{\infty}}-\frac{1}{M_{t}}\right)=-k_{m s} M_{\infty} t+\ln \left(\frac{1}{M_{\infty}}-\frac{1}{M_{0}}\right)
$$

where $k_{m s}$ is the reaction rate constant for midpoint-chain scission reaction model. A linear line is obtained by plotting $\ln \left(1 / M_{\infty}-1 / M_{t}\right)$ versus $t$ where the rate constant can be obtained from the slope.

\section{Results and Discussion}

\subsection{Effect of temperature on depolymeri- zation}

The variations of the number-average molecular weight of s-carrageenan with sonication time at various temperatures are depicted in Figure 2. The molecular weight drops rapidly within the first 20 minutes but decreases slowly and at the end of the treatment the molecular weight approaches different limiting values for different temperatures. The results, as depicted in Figure 2, show that at higher temperatures, the molecular weight is lower

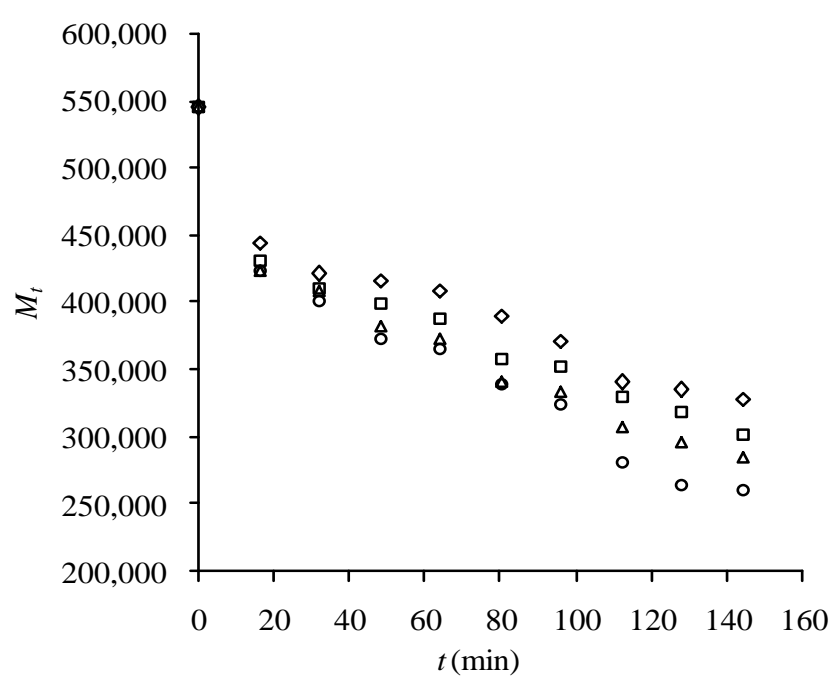

Figure 2. Variation of number-average molecular weight of $\mathrm{K}$-carrageenan with time of sonication at $30^{\circ} \mathrm{C}(\diamond), 40^{\circ} \mathrm{C}(\square), 50^{\circ} \mathrm{C}(\Delta)$, and $60^{\circ} \mathrm{C}(\circ)$ than that at lower temperatures. It means that the extent of depolymerization at higher temperatures is higher as compared to lower temperatures.

The results are contradicted with those obtained by several groups of researcher who found that the extent of reaction decreased with increasing temperatures [29, 37-39]. They explained that the negative effect of temperature could be attributed to cavitation. As the temperature of the solution increases, more solvent vapor enters the cavitation bubble during the expansion and exerts a cushioning effect during the collapse leading to diminishing the intensity of the shock wave. It will reduce the jet velocity, which will further lessen degradation at higher temperatures [31, 37].

However, some other groups of researchers reported similar results to this work where temperature gives positive effect on ultrasoundassisted depolymerization [40-44]. In general, ultrasound-assisted degradation of organic polymers takes place via two mechanism, i.e., homolytic bond breaking and reaction with radicals [45-47]. The homolytic bond breaking reaction is usually caused by the cavitation of microbubbles accompanied with extremely high temperature (up to $5000{ }^{\circ} \mathrm{C}$ ) and pressure (about $5 \times 10^{7} \mathrm{~Pa}$ ) [12], which will lead to the second mechanism, i.e. the generation of $\mathrm{H} \cdot$ and $\mathrm{OH}$. radicals through thermal dissociation of water at the bubble/water interface. The main reactions during sonication are described in Equations (9-11) [45].

$$
\begin{aligned}
& \mathrm{H}_{2} \mathrm{O} \rightarrow \mathrm{H} \bullet+\mathrm{OH}^{\bullet} \\
& \mathrm{H} \bullet+\mathrm{H} \bullet \rightarrow \mathrm{H}_{2} \\
& \mathrm{OH} \bullet+\mathrm{OH} \bullet \rightarrow \mathrm{H}_{2} \mathrm{O}_{2}
\end{aligned}
$$

Both $\mathrm{OH} \cdot$ radical and hydrogen peroxide are strong oxidizing agents. Even in a very low concentration, both $\mathrm{OH} \bullet$ and $\mathrm{H}_{2} \mathrm{O}_{2}$ can oxidize organic polymer such as K-carrageenan [47] causing random degradation [37]. This oxidation reaction, as other chemical reactions, is remarkably accelerated as the temperature rises [48]. The temperature effect can also be related to the viscosity of the reaction mixture. At lower temperature the viscosity of aqueous solution is higher than that of higher temperature. A certain amount of energy is consumed in the process of disaggregation [41]. Therefore, increasing the mixture temperature during sonication will lead to more $\mathrm{k}$-carrageenan molecules degraded as observed in Figure 2. 


\subsection{Effect of temperature on reaction ki- netics}

Two kinetics models (Equations (7) and (8)) are employed in this work to describe the ultrasound-assisted depolymerization of $\mathrm{K}$ carrageenan. Plot of $\ln 1 / M_{t}$ versus $t$ and $\ln$ $\left(1 / M_{\infty}-1 / M_{t}\right)$ versus $t$ at various temperatures depicted in Figure 3, clearly show excellent linearity. The depolymerization rate constants, the limiting molecular weights, and correlation factors for both models at various temperatures are listed in Table 1.

The results presented in Table 1 show that both models have comparable correlation coefficients, however, the correlation coefficient of the midpoint-chain scission model is slightly larger than that of pseudo-first order model. The percent of average absolute deviation (\%AAD) of both models are also calculated. It is

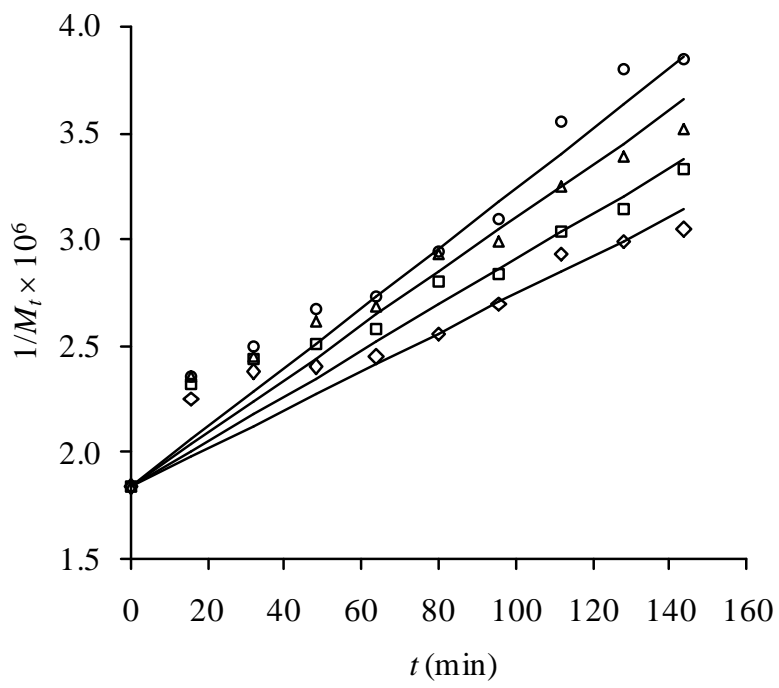

(a) defined as Equation (12).

$\% A A D=\left|\frac{Y_{\exp }-Y_{\text {calc }}}{Y_{\text {exp }}}\right| \times 100 \%$

where $Y$ is the left-hand side of Equation (7) and Equation (8) for pseudo-first-order model and midpoint-chain scission model, respectively. Subscript exp and calc refer to experimental and calculated values, respectively. It is clear from Table 1 that the overall \%AAD of midpoint-chain scission model is much smaller than that of pseudo-first-order model. It indicates that midpoint-chain scission model is more suitable for describing ultrasound-assisted depolymerization. It means that sonication leads to midpoint-chain scission of $\mathrm{k}$-carrageenan molecules.

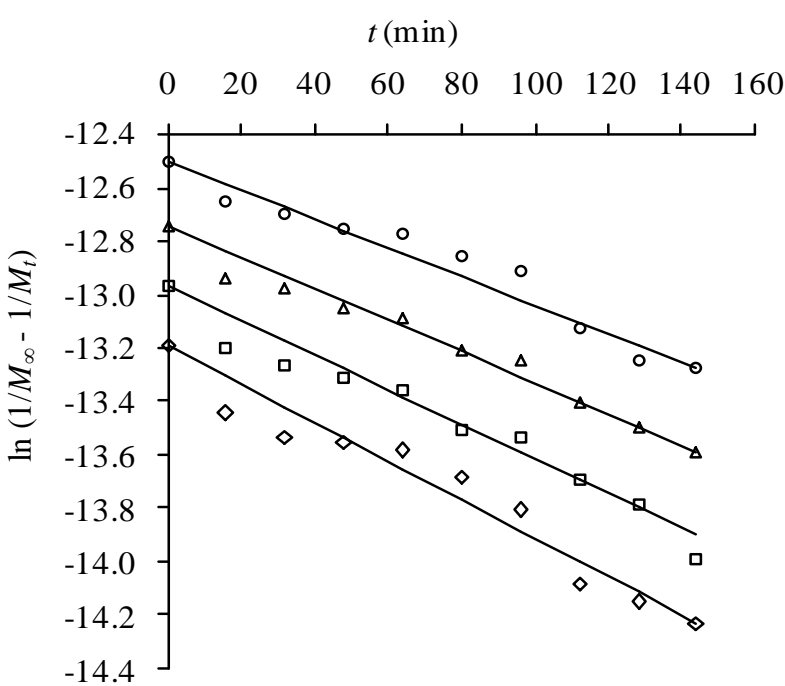

(b)

Figure 3. Time dependencies of (a) $1 / M_{t}$ according to pseudo-first-order model and (b) $\ln \left(1 / M_{\infty}-1 / M_{t}\right)$ according to midpoint-chain scission model for $\mathrm{k}$-carrageenan at $30^{\circ} \mathrm{C}(\diamond), 40^{\circ} \mathrm{C}(\square), 50^{\circ} \mathrm{C}(\Delta)$, and $60^{\circ} \mathrm{C}$ (०)

Table 1. Kinetics parameters for pseudo-first-order and midpoint-chain scission models

\begin{tabular}{|c|c|c|c|c|c|c|c|}
\hline \multirow{2}{*}{$\begin{array}{c}\text { Temperature } \\
\left({ }^{\circ} \mathrm{C}\right)\end{array}$} & \multicolumn{3}{|c|}{ Pseudo-first-order model } & \multicolumn{4}{|c|}{ Midpoint-chain scission model } \\
\hline & $\begin{array}{c}k_{p f} \\
\left(\min ^{-1}\right)\end{array}$ & $R^{2}$ & $\% \mathrm{AAD}$ & $\begin{array}{c}k_{m s} \\
\left(\mathrm{~mol} \mathrm{~g}^{-1} \mathrm{~min}^{-1}\right) \\
\end{array}$ & $M_{\infty}$ & $R^{2}$ & $\% \mathrm{AAD}$ \\
\hline 30 & $1.74 \times 10^{-6}$ & 0.94 & 3.59 & $2.11 \times 10^{-8}$ & 240,000 & 0.95 & 0.33 \\
\hline 40 & $2.05 \times 10^{-6}$ & 0.95 & 4.12 & $2.24 \times 10^{-8}$ & 210,000 & 0.97 & 0.25 \\
\hline 50 & $2.42 \times 10^{-6}$ & 0.97 & 4.09 & $2.47 \times 10^{-8}$ & 190,000 & 0.98 & 0.19 \\
\hline 60 & $2.69 \times 10^{-6}$ & 0.97 & 3.95 & $2.63 \times 10^{-8}$ & 160,000 & 0.96 & 0.26 \\
\hline Overall & & 0.96 & 3.94 & & & 0.97 & 0.26 \\
\hline
\end{tabular}


As presented in Table 1, the limiting molecular weight $\left(M_{\infty}\right)$ decreases as temperature increases. It is shown in Figure 4 that the limiting molecular weight is a linear function of temperature, and it can be presented by Equation (13).

$$
M_{\infty}=-2600 T+10^{6}
$$

with a correlation coefficient of 0.99. As temperature increases, the oxidation reaction by hydroxyl radical which leads to random scission of k-carrageenan increases as well. It means that at higher temperature more $\mathrm{k}$ carrageenan are degraded, hence the final molecular weight will be smaller.

The rate constant for midpoint-chain scission model, $k_{m s}$, is slightly influenced by temperature. It rises from $2.11 \times 10^{-8}$ to $2.63 \times 10^{-8}$ mol g-1 $\mathrm{min}^{-1}$ as the temperature rises from 30 to $60{ }^{\circ} \mathrm{C}$, or in average it only increases 1.1 fold for a temperature increment of $10{ }^{\circ} \mathrm{C}$. The effect of temperature on the rate constant of ultrasound-assisted depolymerization is much lower than that of thermal depolymerization and acid hydrolysis. Singh and Jacobson [12] who degradated $\mathrm{k}$-carrageenan by acid hydrolysis in a $\mathrm{LiCl} / \mathrm{HCl} \mathrm{pH} 2$ buffer solution found that the rate constant increased 3.8 fold for every $10^{\circ} \mathrm{C}$ of temperature increment, while Lai et al. [11] found 2.3 fold for thermal depolymerization of $\mathrm{k}$-carrageenan. The smaller effect of temperature on sonicated depolymerization compared to acid and thermal depolymerizations is mostly caused by the effect of cavitation

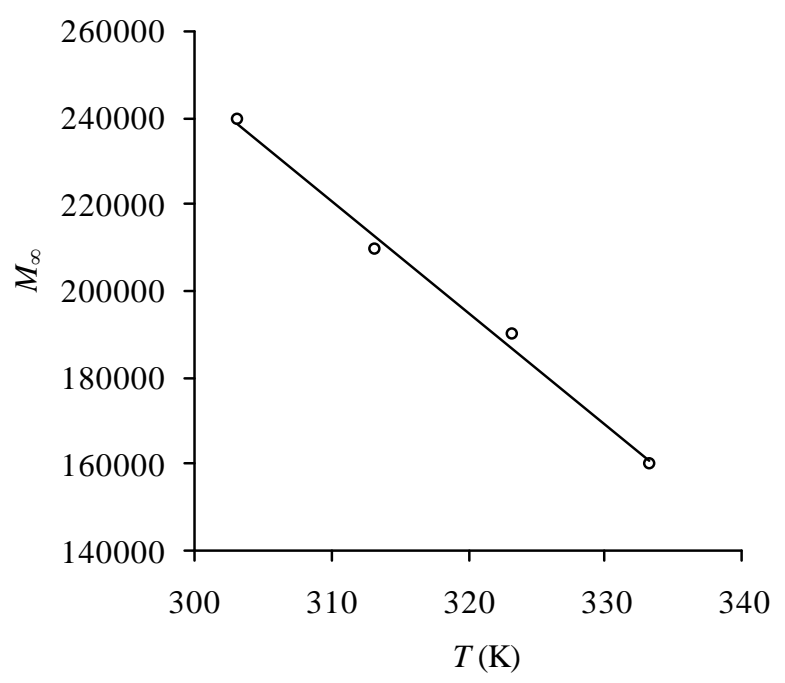

Figure 4. Effect of temperature on the limiting molecular weight during ultrasound-assisted degradation $\mathrm{k}$-carrageenan as explained above.

The temperature dependence of the $k_{m s}$ is given by the Arrhenius law as presented in Equations (14-15).

$$
\begin{aligned}
& k_{m s}=A e^{-E_{a} / R T} \\
& \text { or } \\
& \ln k_{m s}=\ln A-\frac{E_{a}}{R T}
\end{aligned}
$$

where $A$ and $E_{a}$ are pre-exponential factor and activation energy, respectively. Plot of $\ln k_{m s}$ versus $1 / T$ will result in a linear line, as depicted in Figure 5, with correlation coefficient of 0.99. The constants, $A$ and $E_{a}$, can be obtained from the intercept and slope, which are $2.68 \times 10^{-7} \mathrm{~mol} \mathrm{~g}^{-1} \mathrm{~min}^{-1}$ and $6.43 \mathrm{~kJ} \mathrm{~mol}^{-1}$, respectively.

Most of the reactions have $E_{a}$ value ranging from 40 to $400 \mathrm{~kJ} \mathrm{~mol}^{-1}$. If the value is less than $40 \mathrm{~kJ} \mathrm{~mol}^{-1}$, the reaction will complete very rapidly [44]. The activation energy obtained in this work is $6.43 \mathrm{~kJ} \mathrm{~mol}^{-1}$, while the activation energy for thermal degradation of $\mathrm{k}$-carrageenan obtained by Lai et al. is $99.6 \mathrm{~kJ} \mathrm{~mol}^{-1}$ [11]. The smaller value of activation energy for ultrasound-assisted depolymerization shows that ultrasound remarkably decreases the energy barrier required for the reaction [44]. The great reduction in $E_{a}$ value by ultrasonic treatment indicates that the ultrasound-assisted reaction occur very easily. However, the work of Lai et al. [11] had revealed that the pre-exponential factor of the

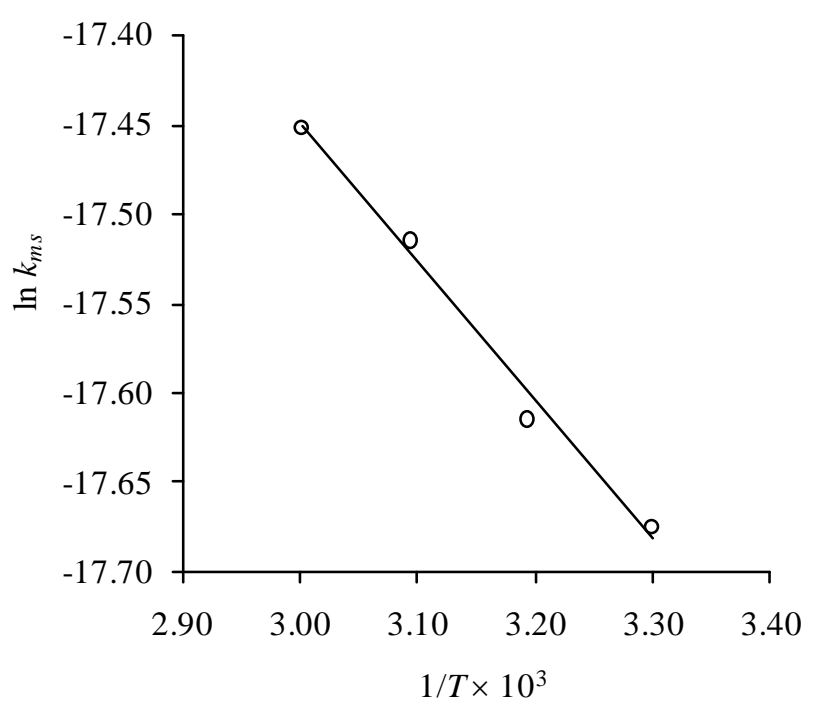

Figure 5. Arrhenius plot of temperature dependence of the rate coefficient $k_{m s}$ 
Arrhenius correlation was $4.25 \times 10^{9} \mathrm{~min}^{-1}$ which is much higher than that of this work. It must have implication to the reaction rate.

To compare the performance of thermal and ultrasound-assisted depolymerization, the half life of $\mathrm{k}$-carrageenan undergoing both processes are calculated. Suppose that we have $\mathrm{k}$ carrageenan with initial molecular weight of 544,980 as used in this work that undergoes two different processes, i.e. thermal and ultrasound-assisted depolymerizations, at various temperatures. The half life $\left(t_{1 / 2}\right)$ of $\mathrm{K}$ carrageenan undergoing thermal degradation is calculated using Equation (7) with $A$ and $E_{a}$ are $9.47 \times 10^{9} \mathrm{~min}^{-1}$ and $99.6 \mathrm{~kJ} \mathrm{~mol}^{-1}$, respectively, while that for ultrasound-assisted degradation is calculated using Equation (8) with $A$ and $E_{a}$ are $2.68 \times 10^{-7} \mathrm{~mol} \mathrm{~g}^{-1} \mathrm{~min}^{-1}$ and $6.43 \mathrm{~kJ}$ $\mathrm{mol}^{-1}$, respectively. The results are presented in Figure 6. At lower temperatures $\left(<72.2^{\circ} \mathrm{C}\right)$, the half life of $\mathrm{k}$-carrageenan undergoing ultrasound-assisted depolymerization is smaller than that of thermal depolymerization. It means that ultrasound-assisted depolymerization is faster than thermal depolymerization at lower temperatures.

\subsection{Effect of temperature and ultrasound treatment on the thermodynamic parame- ters}

According to transition state theory, the rate constant is related to the changes in enthalpy of activation $\left(\Delta H^{\ddagger}\right)$ and entropy of activation $(\Delta S \ddagger)$ as presented by the Eyring equation [49].

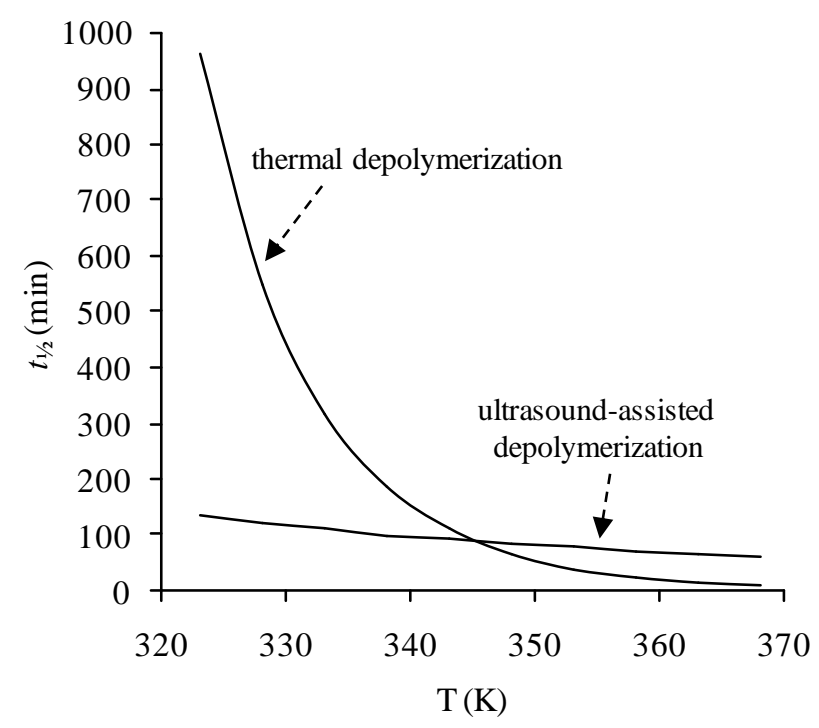

Figure 6. Half life of $\mathrm{x}$-carrageenan undergoing ultrasound-assisted depolymerization (this work) and thermal depolymerization [22]

$$
k_{m s}=\frac{k_{B} T}{h} e^{\Delta S^{\ddagger} / R} e^{\Delta H^{\ddagger} / R T}
$$

where $k_{B}$ is the Boltzman constant $\left(1.3806 \times 10^{-23} \mathrm{~J} \mathrm{~K}^{-1}\right)$, and $h$ is the Planck constant (6.6207×10-34 J.s). The Equation (16) can be written as in Equation (17).

$$
\ln \frac{k_{m s}}{T}=-\frac{\Delta H^{\ddagger}}{R T}+\ln \frac{k_{B}}{h}+\frac{\Delta S^{\ddagger}}{R}
$$

A plot of $\ln \left(k_{m s} / T\right)$ versus $1 / T$ will result in a linear line with correlation coefficient of 0.97 as depicted in Figure 7.

From the slope and the intercept of the line, enthalpy of activation $(\Delta H \ddagger)$ and entropy of activation $\left(\Delta S^{\ddagger}\right)$ can be deduced. The values of $\Delta H *$ and $\Delta S \ddagger$ for ultrasound-assisted depolymerization are $3.79 \mathrm{~kJ} \mathrm{~mol}^{-1}$ and $-413.5 \mathrm{~J} \mathrm{~mol}^{-1}$ $\mathrm{K}^{-1}$, respectively. For thermal degradation, $\Delta H \ddagger$ and $\Delta S \ddagger$, as calculated from the results of Lai et al. [11], are $96.41 \mathrm{~kJ} \mathrm{~mol}^{-1}$ and $-132.6 \mathrm{~J}$ $\mathrm{mol}^{-1} \mathrm{~K}^{-1}$, respectively. The results for both reactions are presented in Table 2 .

The enthalpy of activation $(\Delta H *)$ is the difference between the enthalpy of the transition state and the sum of the enthalpies of the reactants in the ground state. A large value of enthalpy of activation indicates that a large amount of energy to stretch, squeeze or even break the chemical bonds is needed for the formation of the transition state. The value of

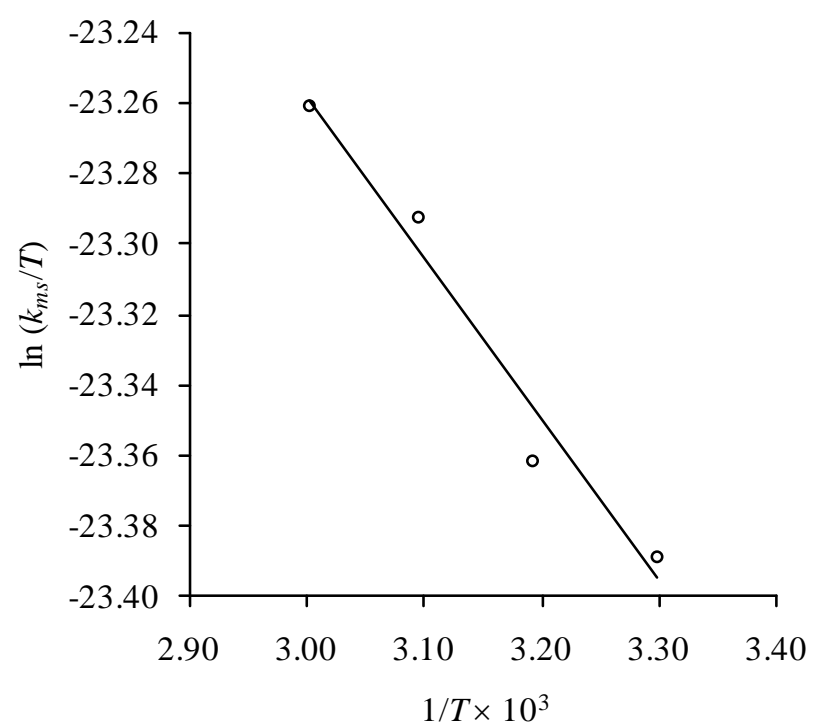

Figure 7. Plot of $\ln \left(k_{m s} / T\right)$ versus $1 / T$ for Eyring equation 
$\Delta H^{\ddagger}$ of the ultrasound-assisted depolymerization is $96.1 \%$ lower than that of thermal process. The decrease of $\Delta H^{\ddagger}$ accompanying the sonication can be explained by a decrease of the energy barrier of the reaction. Sonication may induce cavitation effect which creates enormous shear forces that can break covalent bond [25, 43]. It means that sonication can make the reactants reach transition state with less energy, which is translated to the decrease of $\Delta H \vDash[50]$.

The value of $\Delta S^{\ddagger}$ of the ultrasound-assisted depolymerization is lowered by $211.8 \%$ compared to that of thermal process. Large and negative value of $\Delta S^{\ddagger}$ indicates that the formation of the transition state requires the $\mathrm{k}$ carrageenan molecules to adopt precise conformations relative to the shear force around the collapsing bubbles [51]. The decrease in $\Delta S^{\ddagger}$ is also an indication of more orderly distributed $\mathrm{K}$-carrageenan molecules after ultrasound irradiation [50]. Smaller value of $\Delta S^{\ddagger}$ confirms the smaller value of the pre-exponential factor of the Arrhenius equation, $A$, for the ultrasonic depolymerization, as the pre-exponential factor is proportional to $\exp \left(\Delta S^{\ddagger} / \mathrm{R}\right)$ [52].

The values of $\Delta G^{\ddagger}$ is calculated using the fundamental equation [49] in Equation (18).

$$
\Delta G^{\ddagger}=\Delta H^{\ddagger}-T \Delta S^{\ddagger}
$$

The values of $\Delta G^{\ddagger}$ of thermal and ultrasoundassisted depolymerizations, as presented in Table 2, slightly increase as the temperature increases. It is a consequence of the form of equation (18). The value of $\Delta G^{\ddagger}$ of the ultrasoundassisted depolymerization is $2.4 \%$ in average lower than that of thermal process at $30^{\circ} \mathrm{C}$. The difference becomes smaller as the temperature increases. The same trend was also found by Jin et al. [50]. These decreases in $E_{a}, \Delta H^{\ddagger}, \Delta S^{\ddagger}$, and $\Delta G^{\ddagger}$ can be attributed to the ultrasonically induced breakage of non-covalent bonds in $\mathrm{k}$ carrageenan molecules and to the oxidative reaction of $\mathrm{k}$-carrageenan by hydroxyl radical $[42,50]$.

\section{Conclusions}

The ultrasonic depolymerization of $\mathrm{k}$ carrageenan has been investigated. The molecular weight decreases rapidly within the first 20 minutes then slowly approaches different limiting molecular weight for different temperatures. The extent of depolymerization is higher at higher temperatures.

Correlated using the mid-scission model with average coefficient of correlation of 0.97 , the rate constant only increases 1.1 fold for a temperature increment of $10^{\circ} \mathrm{C}$. The activation energy, $E_{a}$, and pre-exponential factor, $A$, for the reaction are $6.43 \mathrm{~kJ} \mathrm{~mol}^{-1}$ and $2.68 \times 10^{-7} \mathrm{~mol} \mathrm{~g}^{-1} \mathrm{~min}^{-1}$, respectively. When compared to thermal degradation, the half life $\left(t_{1 / 2}\right)$, of ultrasound-assisted depolymerization at lower temperatures $\left(<72.2^{\circ} \mathrm{C}\right)$ is smaller. It means that ultrasound-assisted depolymerization is faster than thermal depolymerization at lower temperatures.

Thermodynamic review of the reaction shows that the $\Delta H^{\ddagger}, \Delta S^{\ddagger}$, and $\Delta G^{\ddagger}$ of the ultrasound-assisted depolymerization are lower than those of thermal process. Compared to thermal process, the, and of the ultrasoundassisted depolymerization are lower by $96.1 \%$, $211.8 \%$, and $2.4 \%$, respectively. These decreases are related to the ultrasonically induced breakage of non-covalent bonds in $\mathrm{k}$ carrageenan molecules.

\section{Acknowledgments}

The authors acknowledge the financial support from the Directorate General of

Table 2. Thermodynamic parameters for ultrasound-assisted and thermal depolymerization

\begin{tabular}{ccc}
\hline & Thermal depolymerization [11] & $\begin{array}{c}\text { Ultrasound-assisted depolymerization } \\
\text { (this work) }\end{array}$ \\
\hline$\Delta H^{\ddagger}\left(\mathrm{kJ} \mathrm{mol}^{-1}\right)$ & 96.41 & 3.79 \\
$\Delta S^{\ddagger}\left(\mathrm{J} \mathrm{mol}^{-1} \mathrm{~K}^{-1}\right)$ & -132.6 & -413.5 \\
$\Delta G^{\ddagger}\left(\mathrm{kJ} \mathrm{mol}^{-1}\right)$ & & \\
at $30^{\circ} \mathrm{C}$ & 136.61 & 129.15 \\
at $40^{\circ} \mathrm{C}$ & 137.94 & 133.29 \\
at $50^{\circ} \mathrm{C}$ & 139.26 & 137.42 \\
at $60^{\circ} \mathrm{C}$ & 140.59 & 141.56 \\
\hline
\end{tabular}


Higher Education, Ministry of Education and Culture of Republic of Indonesia through a project with a letter of agreement number: 332/SP2H/PL/DIT.LITABMAS/IX/2013. The authors also acknowledge the technical support of Shodaqta Saori and Gus Ihsan Wahid.

\section{References}

[1] Campo, V. L., Kawano, D. F., da Silva Jr., D.B., Carvalho, I. (2009). Carrageenans: Biological Properties, Chemical Modifications and Structural Analysis - A Review. Carbohydrate Polymers, 77: 167-180.

[2] Yao, Z., Wu, H., Zhang, S., Du, Y. (2014). Enzymatic Preparation of $\mathrm{k}$-Carrageenan Oligosaccharides and Their Anti-Angiogenic Activity. Carbohydrate Polymers, 101: 359-367.

[3] Haijin, M. Xiaolu, J., Huashi, G. (2013). A kcarrageenan Derived Oligosaccharide Prepared by Enzymatic Degradation Containing Anti-tumor Activity. Journal of Applied Phycology, 15: 297-303.

[4] Raman, R., Doble, M. (2015). к-Carrageenan from marine red algae, Kappaphycus alvarezii - A Functional Food to Prevent Colon Carcinogenesis. Journal of Functional Foods, 15: 354-364.

[5] Carlucci, M. J., Ciancia, M., Matulewicz, M. C., Cerezo, A. S., Damonte, E. B. (1999). Antiherpetic Activity and Mode of Action of Natural Carrageenans of Diverse Structural Types. Antiviral Research, 43: 93-102.

[6] Yamada, T., Ogamo, A., Saito, T., Uchiyama, H., Nakagawa, Y. (2000). Preparation of OAcylated Low-Molecular-Weight Carrageenans with Potent Anti-HIV Activity and Low Anticoagulant Effect. Carbohydrate Polymers, 41: 115-120.

[7] Chiu, Y.-H., Chan, Y.-L., Tsai, L.-W., Li, T.-L., Wu, C.-J. (2012). Prevention of Human Enterovirus 71 Infection by Kappa Carrageenan. Antivar Research, 95: 128-134.

[8] Silva, F. R. F., Dore, C. M. P. G., Marques, C. T., Nascimento, M. S., Benevides, N. M. B., Rocha, H. A. O., Chavante, S. F., Leite, E. L. (2010). Anticoagulant Activity, Paw Edema and Pleurisy Induced Carrageenan: Action of Major Types of Commercial Carrageenans. Carbohydrate Polymers, 79: 26-33.

[9] Gomez-Ordonez, E., Jimenez-Escrig, A., Rupérez, P. (2014). Bioactivity of Sulfated Polysaccharides from the Edible Red Seaweed Mastocarpus stellatus. Bioactive Carbohydrates and Dietary Fibre, 3: 29-40.

[10] de Souza, L. A. R., Dore, C. M. P. G., Castro, A. J. G., de Azevedo, T. C. G., de Oliveira, M. T. B., Moura, M. F. V., Benevides, N. M. B.,
Leite, E. L. (2012). Galactans from the Red Seaweed Amansia multifida and Their Effects on Inflammation, Angiogenesis, Coagulation and Cell Viability. Biomedicine \& Preventive Nutrition, 2: 154-162.

[11] Lai, V. M.-F., Lii, C.-Y., Hung, W.-L., Lu, T.J. (2000). Kinetic Compensation Effect in Depolymerisation of Food Polysaccharides. Food Chemistry, 68: 319-325.

[12] Singh, S. K., Jacobson, S. P. (1994). Kinetics of Acid Hydrolysis of $\mathrm{k}$-Carrageenan as Determined by Molecular Weight (SECMALLSRI), Gel Breaking Strength, and Viscosity Measurements. Carbohydrate Polymers, 23: 89-103.

[13] Karlsson, A., Singh, S. K. (1999). Acid Hydrolysis of Sulphated Polysaccharides. Desulphation and the Effect on Molecular Mass. Carbohydrate Polymers, 38: 7-15.

[14] Yang, B., Yu, G., Zhao, X., Jiao, G., Ren, S., Chai, W. (2009). Mechanism of Mild Acid Hydrolysis of Galactan Polysaccharides with Highly Ordered Disaccharide Repeats Leading to A Complete Series of Exclusively Oddnumbered Oligosaccharides. Federation of European Biochemical Societies Journal, 276: 2125-2137. doi:10.1111/j.17424658.2009.06947.x.

[15] Tang, F., Chen, F., Li, F. (2013). Preparation and Potential in Vivo Anti-influenza Airus Activity of Low Molecular-Weight KCarrageenans and Their Derivatives. Journal of Applied Polymer Science, 127: 21102115. doi: 10.1002/app.37502.

[16] Kalitnik, A. A., Barabanova, A. O. B., Nagorkaya, V. B., Reunov, A. V., Glazunov, V. P., Solov'eva, T. F., Yermak, I. M. (2013). Low Molecular Weight Derivatives of Different Carrageenan Types and Their Antiviral Activity. Journal of Applied Phycology, 25: 65-72.

[17] Collén, P. N., Lemoine, M., Daniellou, R., Guégan, J.-P., Paoletti, S., Helbert, W. (2009). Enzymatic Degradation of KCarrageenan in Aqueous Solution. Biomacromolecules, 10: 1757-1767

[18] Wu, S.-J. (2012). Degradation of KCarrageenan by Hydrolysis with Commercial a-Amylase. Carbohydrate Polymers, 89: 394-396.

[19] Abad, L. V., Kudo, H., Saiki, S., Nagasawa, N., Tamada, M., Fub, H., Muroya, Y., Lin, M., Katsumura, Y., Relleve, L. S., Aranilla, C. T., DelaRosa, A. M. (2010). Radiolysis Studies of Aqueous k-Carrageenan. Nuclear Instruments and Methods in Physics Research B, 268: 1607-1612.

[20] Lii, C.-Y., Chen, C.-H., Yeh, A.-I., Lai, V. M.F. (1999). Preliminary Study on the Degra- 
dation Kinetics of Agarose and Carrageenans by Ultrasound. Food Hydrocolloids, 13: 477481.

[21] Taghizadeh, M. T., Abdollahi, R. (2015). Influence of Different Degradation Techniques on the Molecular Weight Distribution of $\mathrm{K}$ Carrageenan. International Journal of Biochemistry and Biophysics, 3: 25-33. DOI: 10.13189/ijbb.2015.030301

[22] Czechowska-Biskup, R., Rokita, B., Lotfy, S., Ulanski, P., Rosiak, J. M. (2005). Degradation of Chitosan and Starch by $360-\mathrm{kHz}$ Ultrasound. Carbohydrate Polymers, 60: 175-184.

[23] Awad, T. S., Moharram, H. A., Shaltout, O. E., Asker, D., Youssef, M. M. (2012), Applications of Ultrasound in Analysis, Processing and Quality Control of Food: A Review. Food Research International, 48: 410-427.

[24] Akyüz, A., Catalgil-Giz, H., Giz, A. T. (2008). Kinetics of Ultrasonic Polymer Degradation: Comparison of Theoretical Models with OnLine Data. Macromolecular Chemistry and Physics, 209: 801-809.

[25] Suslick, K. S., Flannigan, D. (2008). Inside a Collapsing Bubble: Sonoluminescence and the Conditions During Cavitation. Annual Review of Physical Chemistry, 59: 659-683.

[26] Suslick, K. S., Didenko, Y., Fang, M. M., Hyeon, T. T., Kolbeck, K. J., McNamara III, W. B., Mdleleni, M. M., Wong, M. (1999). Acoustic cavitation and its chemical consequences. Philosophical Transactions of the Royal Society A, 357: 335-353.

[27] Didenko, Y. T., McNamara III, W. B., Suslick, K. S. (1999). Hot Spot Conditions during Cavitation in Water. Journal of the American Chemical Society, 121: 5817-5818.

[28] Madras, G., Kumar, S., Chattopadhyay, S. (2000). Continuous Distribution Kinetics for Ultrasonic Degradation of Polymers. Polymer Degradation and Stability, 69: 73-78.

[29] Chakraborty, J., Sarkar, J., Kumar, R., Madras, G. (2004). Ultrasonic Degradation of Polybutadiene and Isotactic Polypropylene. Polymer Degradation and Stability, 85: 555558.

[30] Popa-Nita, S., Lucas, J.-M., Ladavière, C., David, L., Domard, A. (2009). Mechanisms Involved During the Ultrasonically Induced Depolymerization of Chitosan: Characterization and Control. Biomacromolecules, 10: 12031211.

[31] Zhang, L., Ye, X., Ding, T., Sun, X., Xu, Y., Liu, D. (2013). Ultrasound Effects on the Degradation Kinetics, Structure and Rheological Properties of Apple Pectin. Ultrasonics Sonochemistry, 20: 222-231.
[32] Guo, X., Ye, X., Sun, Y., Wu, D., Wu, N., Hu, Y., Chen, S. (2014). Ultrasound Effects on the Degradation Kinetics, Structure, and Antioxidant Activity of Sea Cucumber Fucoidan. Journal of Agricultural and Food Chemistry, 62: 1088-1095.

[33] Peterson and, G. I., Boydston, A. J. (2014). Kinetic Analysis of Mechanochemical Chain Scission of Linear Poly(phthalaldehyde). Macromolecular Rapid Communications, 35: 1611-.

[34] Yan, J.-K., Peia, J.-J., Ma, H.-L., Wang, Z.B. (2015). Effects of Ultrasound on Molecular Properties, Structure, Chain Conformation and Degradation Kinetics of Carboxylic Curdlan. Carbohydrate Polymers, 121: 6470 .

[35] Vreeman, H. J., Snoeren, T. H. M., Payens, T. A. J. (1980). Physicochemical Investigation of $\mathrm{k}$-Carrageenan in the Random State. Biopolymers, 19: 1357-1354.

[36] Tanford, C. (1961). Physical Chemistry of Macromolecules. John Wiley \& Sons, Inc. New York.

[37] McCoy, B. J., Madras, G. (1997). Degradation Kinetics of Polymers in Solution: Dynamics of Molecular Weight Distributions. AIChE Journal, 43: 802-810.

[38] Mahalik, J. P., Madras, G. (2005). Effect of Alkyl Group Substituents, Temperature, and Solvents on the Ultrasonic Degradation of Poly(n-Alkyl Acrylates). Industrial \& Engineering Chemistry Research, 44: 6572-6577 (2005).

[39] Daraboina, N., Madras, G. (2009). Kinetics of the Ultrasonic Degradation of Poly(Alkyl Methacrylates). Ultrasonics Sonochemistry, 16: 273-279.

[40] Yen, H.-Y., Yang, M.-H. (2003). The Ultrasonic Degradation of Polyacrylamide Solution. Polymer Testing, 22: 129-131.

[41] Kasaai, M. R., Arul, J., Charlet, G. (2008). Fragmentation of Chitosan by Ultrasonic Irradiation. Ultrasonics Sonochemistry, 15: 1001-1008.

[42] Ma, H., Huang, L., Jia, J., He, R., Luo, L., Zhu, W. (2011). Effect of Energy-Gathered Ultrasound on Alcalase. Ultrasonics Sonochemistry, 18: 419-424.

[43] Savitri, E., Juliastuti, S. R., Handaratri, A., Sumarno, Roesyadi, A. (2014). Degradation of Chitosan by Sonication in Very-LowConcentration Acetic Acid. Polymer Degradation and Stability, 110: 344-352.

[44] Prajapat, A. L., Subhedar, P. B., Gogate, P. R. (2016). Ultrasound Assisted Enzymatic Depolymerization of Aqueous Guar Gum Solution. Ultrasonics Sonochemistry, 29: 84-92. 
[45] Nie, M., Wang, Q., Qiu, G. (2008). Enhancement of Ultrasonically Initiated Emulsion Polymerization Rate Using Aliphatic Alcohols As Hydroxyl Radical Scavengers. Ultrasonics Sonochemistry, 15: 222-226.

[46] Guo Z., Feng, R. (2009). Ultrasonic Irradiation-Induced Degradation of LowConcentration Bisphenol A in Aqueous Solution. Journal of Hazardous Materials, 163: 855-860.

[47] Gogate, P. R., Prajapat, A. L. (2015). Depolymerization Using Sonochemical Reactors: A Critical Review. Ultrasonics Sonochemistry, 27: 480-494.

[48] Li, X., Xu, A., Xie, H., Yu, W., Xie, W., Ma, X. (2010). Preparation of Low Molecular Weight Alginate by Hydrogen Peroxide Depolymerization for Tissue Engineering. Carbohydrate Polymers, 79: 660-664.
[49] Hill, Jr., C. G., Root, T. W. (2014). Introduction to Chemical Engineering Kinetics and Reactor Design. John Wiley \& Sons, Inc., Hoboken, New Jersey.

[50] Jin, J., Ma, H., Qu, W., Wang, K., Zhou, C., He, R., Owusu, J., Luo, L. (2015). Effects of Multi-Frequency Power Ultrasound on the Enzymolysis of Corn Gluten Meal: Kinetics and Thermodynamics Study. Ultrasonics Sonochemistry, 27: 46-53.

[51] Cornish-Bowden, A. (2012). Fundamentals of Enzyme Kinetics. Wiley-Blackwell, Weinheim.

[52] Upadhyay, S. K. (2006). Chemical Kinatics and Reaction Dynamics. Anamaya Publishers, New Delhi.

Selected and Revised Papers from The $2^{\text {nd }}$ International Conference on Chemical and Material Engineering 2015 (ICCME 2015) (29-20 September, 2015, Semarang, Indonesia)

(http://econference.undip.ac.id/index.php/iccme/2015) after Peer-reviewed by ICCME 2015 and BCREC Reviewers 